\title{
Prevention and treatment of complications of selective internal radiation therapy: Expert guidance and systematic review
}

Bruno Sangro, MD PhD ${ }^{1,2}$ bsangro@unav.es

Diego Martínez-Urbistondo ${ }^{1}$ dmurbistondo@gmail.com

Lourens Bester, MBChB, FRANCR, FACP ${ }^{3}$ lourensb@bigpond.net.au

Jose I. Bilbao, MD, PhD ${ }^{4}$ jibilbao@unav.es

Douglas M. Coldwell, MD 5 dmcold01@ louisville.edu

Patrick Flamen, MD PhD ${ }^{6}$ patrick.flamen@bordet.be

Andrew Kennedy, MD, FACRO ${ }^{7}$ andrew.kennedy@ sarahcannon.com

Jens Ricke, $\mathrm{MD}^{8}$ jens.ricke@med.ovgu.de

Ricky A. Sharma MD, PhD ${ }^{9}$ ricky.sharma@oncology.ox.ac.uk

1. Liver Unit, Clinica Universidad de Navarra and Instituto de Investigación Sanitaria de Navarra (IdiSNA), Pamplona, Spain.

2. Centro de Investigación Biomédica en Red de Enfermedades Hepáticas y Digestivas, Pamplona Spain.

3. Department of Interventional Radiology, University of New South Wales St. Vincent's Hospital, Darlinghurst, Australia

4. Department of Radiology, Clínica Universidad de Navarra and Instituto de Investigación Sanitaria de Navarra (IdiSNA), Pamplona, Spain.

5. James Graham Brown Cancer Center, University of Louisville, Louisville, KY, USA

This article has been accepted for publication and undergone full peer review but has not been through the copyediting, typesetting, pagination and proofreading process which may lead to differences between this version and the Version of Record. Please cite this article as doi: 10.1002/hep.29207 
6. Department of Nuclear Medicine, Jules Bordet Institute, Brussels, Belgium

7. Physician-in-Chief, Radiation Oncology, Sarah Cannon Research Institute, Nashville,

\section{TN, USA}

8. Department of Radiology and Nuclear Medicine, Otto-von-Guericke University, Magdeburg, Germany

9. University College London, UCL Cancer Institute, London, UK

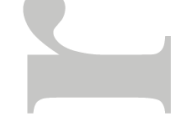

Corresponding author: Bruno Sangro, MD PhD, Liver Unit, Clinica Universidad de Navarra and Instituto de Investigación Sanitaria de Navarra (IdiSNA), Avda. Pio XII, 36. 31008-

Pamplona, Spain; Email: bsangro@unav.es

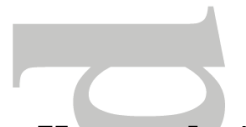

Keywords: hepatocellular carcinoma; liver metastases; radioembolization; safety

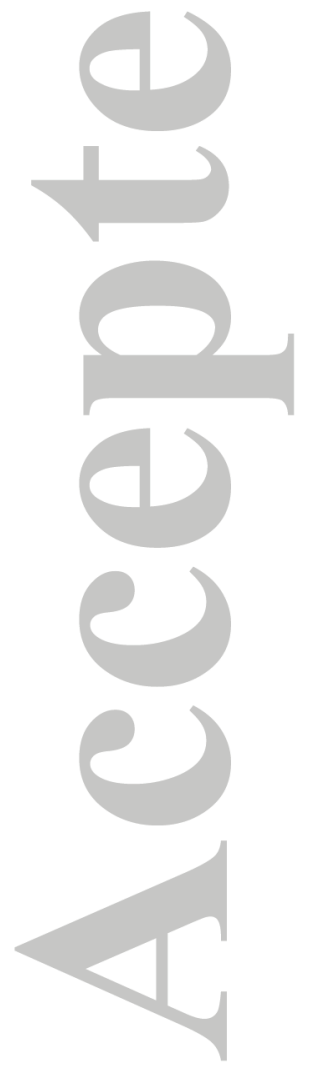




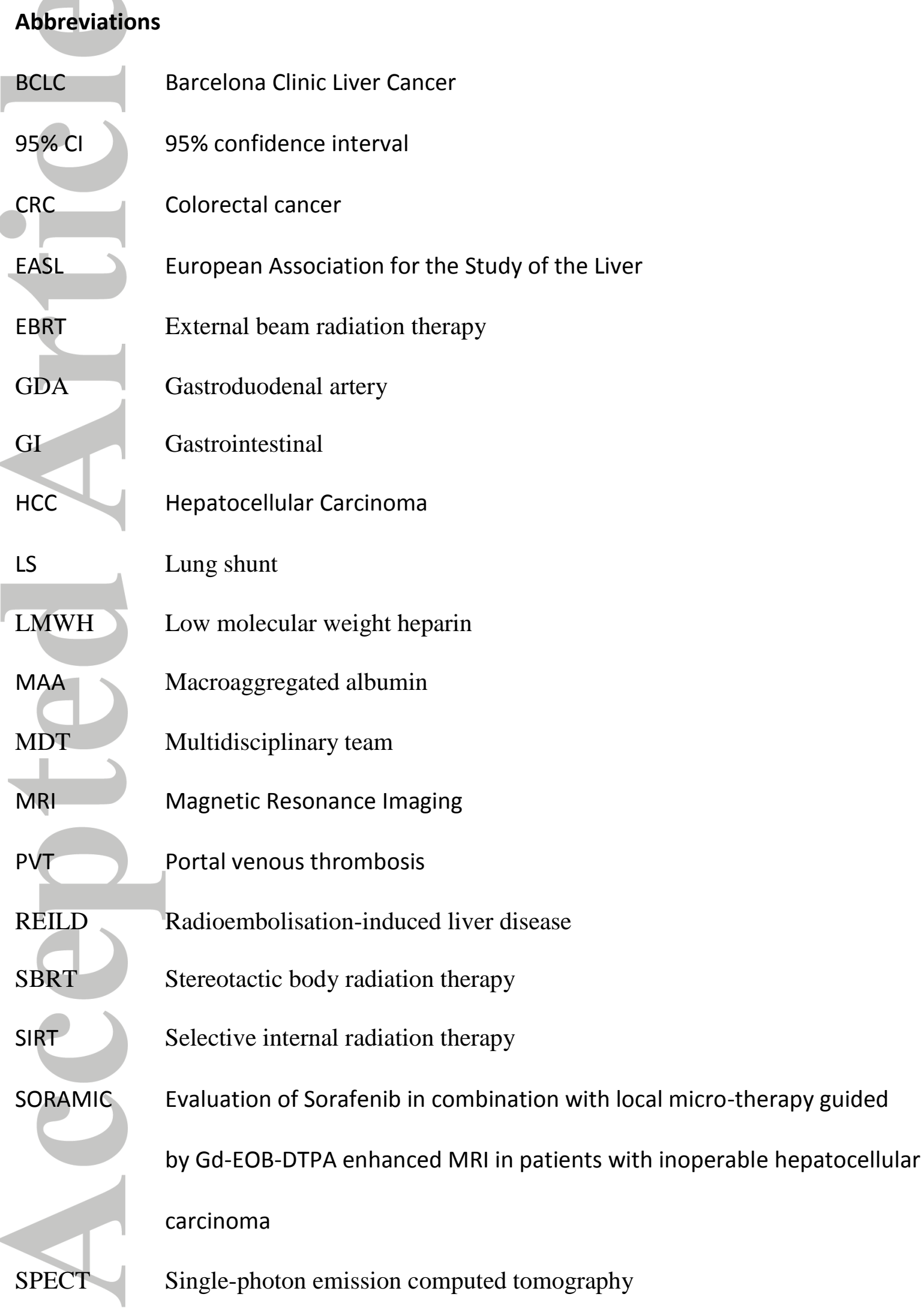


SIRFLOX Randomised phase III trial comparing first-line mFOLFOX6 \pm bevacizumab versus mFOLFOX $6+$ selective internal radiation therapy \pm bevacizumab in patients with metastatic colorectal cancer

SIRTACE
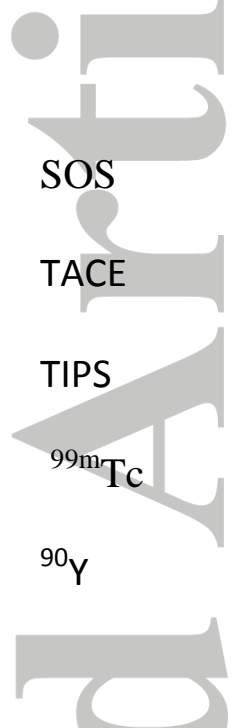

\section{Acknowledgments}

Role of Funding: RAS is funded by the NIHR UCL Biomedical Research Centre, the UCL Cancer Institute Research Trust and Cancer Research UK.

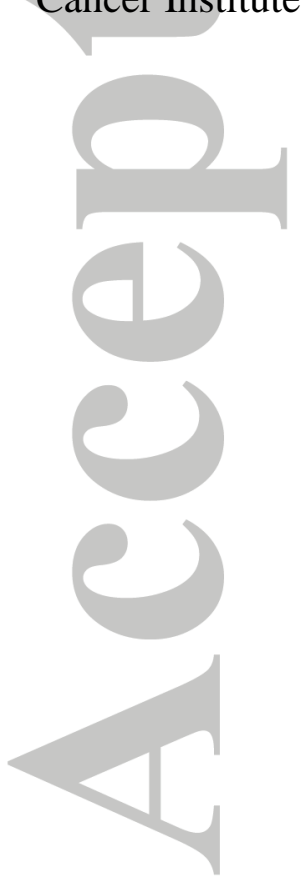




\section{ABSTRACT}

Selective internal radiation therapy (SIRT or radioembolisation) by intraarterial injection of radioactive yttrium-90 $\left({ }^{90} \mathrm{Y}\right)$-loaded microspheres is increasingly used for the treatment of patients with liver metastases or primary liver cancer. The high-dose beta-radiation penetrates an average of only $2.5 \mathrm{~mm}$ from the source so that its effects are limited to the site of delivery.

However the off-target diversion of ${ }^{90} \mathrm{Y}$ microspheres to tissues other than the tumor may lead to complications. The most prominent ones include: radiation gastritis and gastrointestinal (GI)

ulcers, cholecystitis, radiation pneumonitis, and radioembolisation-induced liver disease (REILD). Complications may occur despite careful pre-treatment planning and SIRT demands an expert multidisciplinary team (MDT) approach in order to provide comprehensive care for patients. This review provides recommendations to MDTs on the optimal medical processes in order to ensure the safe delivery of SIRT. Based on the best available published evidence and expert opinion, we recommend the most appropriate strategies for the prevention, early diagnosis and management of potential radiation injury to the liver and to other organs. 


\section{INTRODUCTION}

Selective internal radiation therapy (SIRT, also known as radioembolization), involves the implantation of radiation sources into tumours using radioactive microspheres. Based on published evidence, this procedure is now widely available in specialist centres for the treatment of patients with liver metastases or primary liver cancer. There are two approved products available across continents using either glass or resin microspheres. Once administered into the hepatic artery that feeds liver tumours, they become permanently lodged in the terminal arterioles of tumour where the emitted high dose beta radiation is delivered locally. The offtarget diversion of ${ }^{90} \mathrm{Y}$ microspheres to tissues other than the tumour may lead to complications. The most prominent ones are gastrointestinal (GI) ulcers, radiation pneumonitis, and radioembolisation-induced liver disease (REILD). The aim of this review is to provide recommendations to MDTs on the most appropriate strategies for the prevention, early diagnosis and management of potential radiation injury, based on the best available published evidence and expert opinion.

\section{METHODS}

Recommendations were developed by a panel of experts with extensive experience with SIRT, representing the relevant medical disciplines: medical oncology, interventional radiology, hepatology, radiation oncology and nuclear medicine. The methodology used for the systematic search of the literature and panel discussion of findings and recommendations is available online. In brief, the literature published between January 1990 and June 2016 was systematically searched. A directed appraisal identified 196 papers that were reviewed in detail. An in-depth analysis was performed by complication and all authors had an opportunity to comment on each 
recommendation. A number of recommendations involving technical aspects of the interventional radiology procedures are beyond the scope of this journal and will be discussed
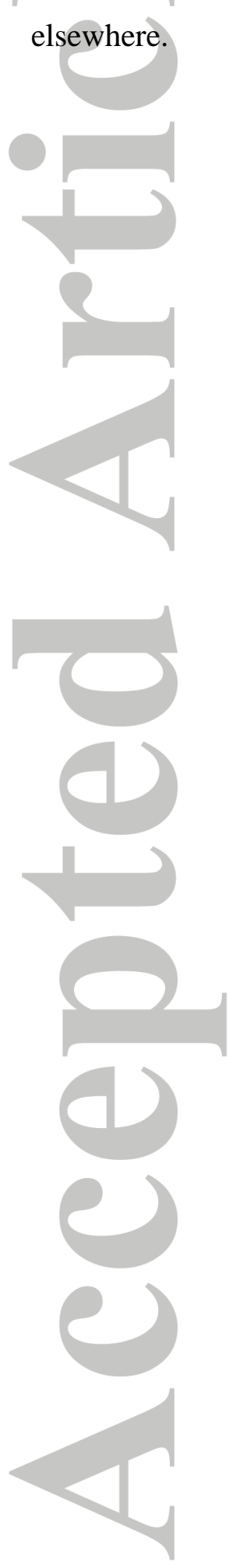


\section{RADIATION PNEUMONITIS}

\section{The medical problem}

Radiation pneumonitis is a very rare but worrisome complication that may occur 1 to 6 months

after SIRT and is characterised by the appearance of restrictive ventilatory dysfunction and bilateral lung infiltrates $(1,2)$ usually with exertional dyspnoea and dry cough. Only six cases $(2$, 3) have ever been reported in detail, none of which were from clinical trials, and of these, 3 were fatal events in a single centre (3).

Microspheres can circumvent the liver sinusoidal network through the tumour or through arteriovenous channels present in the cirrhotic liver, and ultimately reach the lung filter. During the pre-treatment work-up, technetium-99m macroaggregated albumin (MAA) is injected into the hepatic arteries. The lung shunt (LS) is estimated based on the fraction of MAA which becomes deposited in the pulmonary vasculature. The risk of pneumonitis arises when LS exceeds $10 \%$ (3) and is particularly high when it exceeds $20 \%$. Treatment-limiting LS fractions $>20 \%$ are atypical, but more common in HCC than other liver tumours (14\% vs 3\%) (4).

The relevance of subclinical lung damage as a determinant of future cancer treatment is unknown. Further radiation exposure to the lungs is not recommended within 6 months of SIRT. Anecdotal evidence suggests that in cases where a second SIRT procedure is administered within 6-12 months of the first, the maximum tolerated dose in lung should be $<50 \%$ of the dose delivered to the lungs during the first procedure (5).

\section{Prevention of pneumonitis}


Dose reductions of $20 \%$ and $40 \%$ are recommended by the manufacturer of resin microspheres if LS exceeds $10 \%$ or $15 \%$, respectively and SIRT is contraindicated if the lung shunt exceeds 20\%. Strict adherence to these limits largely prevents this complication with no reported cases in recent multicentre retrospective analyses of 606 patients with metastatic colorectal cancer (mCRC) (6), 325 patients with HCC (7) and 112 patients with various tumour types (8). For glass and resin microspheres, an upper limit of 30 Gy to the lung has been empirically established and again shown to largely prevent this complication. Yet, this dosimetric approach has several pitfalls. There are no reliable methods for assessing the real dose of radiation delivered to the lung, a normal tissue complication probability analysis for lung damage is lacking for SIRT, and dosimetric models do not consider functional lung volume. Indeed, pneumonitis may rarely occur in patients with LS < 20\% even if the dose threshold of 30 Gy is not reached, as illustrated in Figure 1. No drug has shown a positive effect in preventing lung damage produced by EBRT. Therefore, prevention of SIRT-induced pneumonitis by medical therapy is not available.

LS is also important because a lower delivered tumour dose will also diminish efficacy. When LS is $\geq 15 \%$, the SIRT team should strongly consider an alternative treatment approach rather than reducing calculated activity of ${ }^{90} \mathrm{Y}$ delivered, or alternatively refer the patient to, or discuss the case with, a centre with high-volume experience.

\section{Diagnostic work-up for suspected pneumonitis}

If lung uptake is observed in imaging procedures following SIRT, we suggest checking the oxygen saturation by pulse oximetry or perform a 6-minute walk test on a weekly or bi-weekly 
basis, and have a chest CT scan done in case of oxygen desaturation or dyspnoea. Similarly, any patient with a LS $>10 \%$ that presents with dyspnoea within the first 3 months after SIRT should have a chest CT. If the characteristic bilateral symmetric ill-defined patchy opacities and groundglass nodularity with relative peripheral/hilar sparing (3) are observed and an infectious or cardiac cause can be ruled out, it is worth starting therapy without delay. Functional tests show a restrictive pattern with an altered diffusing capacity of the lung for carbon monoxide (DLCO).

The decision to perform a broncho-alveolar lavage and/or a transbronchial lung biopsy should be based on the likelihood of alternative diagnosis that may be identified with these procedures.

\section{Treatment of pneumonitis}

Steroids form the mainstay of treatment (Table 1) although there is little supporting evidence. The patient may receive steroids for a minimum period of two weeks followed by slow tapering (9). Oxygen supply may be needed and treatment may be augmented with pentoxifylline, again on a totally empiric basis (3).

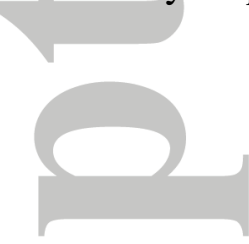

\section{GASTROINTESTINAL ULCERATIONS}

\section{The medical problem}

Radiation-induced GI ulcerations are an uncommon complication of SIRT that presents usually 2-6 weeks after SIRT with symptoms of acute epigastric pain, nausea, vomiting, dyspepsia and sometimes anorexia (10). Ulcers are usually multiple $(0.5-2 \mathrm{~cm}$ in size), but can also be "diffuse" and unmeasurable (11) and often associated with diffuse mucositis (12). They typically have a chronic, insidious course with symptoms persisting for weeks despite 
appropriate therapy. In the largest clinical trial on SIRT, the incidence of GI ulcers was $2.4 \%$ among patients with $\mathrm{mCRC}$ (13). Several retrospective analyses of large cohorts reported a similar incidence of $1.9-3.2 \%(6,7,11,14-16)$. The natural history has been described in detail (12). Symptoms are usually mild-to-moderate and last for 4-10 months despite treatment, but full symptomatic and endoscopic recovery normally occurs as shown in Figure 2. Complications include: pyloric stricture, haemorrhage, severe anaemia with transfusion needs, bilioenteric fistula, and death $(7,11,12,17)$.

${ }^{90} \mathrm{Y}$ microspheres can be found in gastric biopsies obtained months to years after SIRT in asymptomatic patients. The administration of agents with a potential to produce gastric injury to these patients with subclinical GI damage may pose some theoretical concern, particularly antiangiogenics. Among patients with mCRC treated with SIRT plus FOLFOX in a large trial, the rate of bleeding or GI ulcers was reassuringly similar in those that received bevacizumab and those that had not (13).

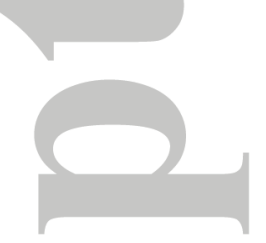

\section{Prevention of GI ulcers}

Prevention of GI complications in SIRT largely depends on the identification of the vascular anatomy that allows microspheres injected into the hepatic arteries to gain access to the stomach or duodenum. A comprehensive evaluation of the liver arterial vasculature, careful evaluation of any MAA uptake that may be located outside the liver, the judicious use of coil embolization of collateral vessels to manage parasitisation/collateralisation, and the prevention of stasis and 
reflux during infusion should minimize the risk of GI ulcers. Yet, they can still occur due to unnoticed or recanalised collateral vessels or changes in flow dynamics during treatment.

Although commonly used, there is no scientific evidence to support the use of proton pump inhibitors (PPI) in the prevention of radiation-induced damage to the GI tract. Routine PPI therapy should not therefore be considered mandatory. If PPI are prescribed, they should be maintained for at least 8 weeks, when SIRT-related GI ulcers usually become symptomatic. Other prophylactic approaches including the use of the prostaglandin E2 inhibitor, misoprostol, or the identification and eradication of Helicobacter pylori prior to SIRT may be considered, but equally lack supporting scientific evidence.

The detection of extrahepatic uptake of radioactivity in post-SIRT imaging procedures that is consistent with GI exposure to radiation deserves special consideration. The limitations in space resolution of these imaging techniques, including but not only the effect of respiratory movements, may produce false positive observations. The use of prophylactic PPI is generally recommended, but gastroscopy does not need to be performed in the absence of significant symptoms. The use of innocuous radioprotective agents such as amifostine might be considered in some cases (18).

\section{Diagnostic work-up for suspected GI ulcerations}

An upper endoscopy should be performed in every patient who develops persistent upper abdominal pain 4 to 8 weeks after SIRT, particularly if pain is associated with nausea, loss of appetite or anaemia. Early gastroscopy is also encouraged for those patients in whom anaemia 
develops or worsens 4-6 weeks after SIRT. Failure to retrospectively detect extrahepatic uptake of radioactivity in the post-SIRT scans in these patients should not lead to delayed evaluation. The presence of multiple mucosal erosions and ulcerations or a single large ulcer, usually associated with diffuse mucositis, and the distribution of the lesions, usually involving the distal gastric body, antrum, pylorus and the duodenal bulb, allow the presumptive diagnosis $(10,12$, 19-23). The poor healing of the radiated site often discourages regular biopsies that will unlikely change patient management.

\section{Treatment of GI ulcerations}

Radiation-induced GI ulceration is poorly responsive to therapy but the most relevant recommendations are summarised in Table 2. Mild-to-moderate symptoms can be treated by dietary modification and starting or increasing to maximal the dose of PPI, the gastroprotective agent Sucralfate, antiemetics, analgesics, and gastric promotility agents such as Domperidone or Cinitapride (12). Nonsteroidal anti-inflammatory drugs and any other medication potentially harmful for the GI mucosa have to be withdrawn. In more severe cases, pain and nausea relief can only be achieved by total parenteral nutrition. When the situation persists for weeks, jejunostomy may provide long-term symptom control until ulcers heal and secure proper nourishment (23). Recurrent GI haemorrhage can be managed by direct endoscopic therapy or selective bland targeted arterial embolisation. Rarely (less than $10 \%$ of cases), perforation or bleeding may require surgical excision of the involved GI tract segment with bypass $(24,25)$.

\section{LIVER COMPLICATIONS}

\section{The medical problem}


Identifying liver toxicity in patients with liver cancer treated with liver-directed therapies is not an easy task. The liver that harbours a cancer is by definition non-healthy. Patients with primary liver cancer usually have a chronic liver disease frequently in the cirrhotic stage. Those with liver metastases from distant cancers quite commonly have steatosis or fibrosis either at diagnosis or after exposure to several chemotherapeutic agents, including oxaliplatin, irinotecan or fluoroderivatives (26). Tumour growth in the liver may per se ultimately impair liver functions. On the other hand, the liver is a multifunctional organ and different variables may reveal liver dysfunction, from laboratory values to organ rigidity to distant signs of portal hypertension.

\section{Radioembolisation-induced liver disease (REILD)}

REILD is a well-defined syndrome characterised by the appearance of jaundice and ascites 4 to 8 weeks after SIRT in the absence of tumour progression or bile duct occlusion (27). REILD is always associated with elevated bilirubin $(>3 \mathrm{mg} / \mathrm{dL})$ with variable increases in alkaline phosphatase and gamma-glutamyl transferase (GGT), and virtually no changes in transaminases

(AST and ALT). This syndrome is clinically distinct from the anicteric ascites caused by EBRT (28). REILD resembles other forms of sinusoidal obstruction syndrome (SOS). Indeed in the most severe cases liver biopsy shows veno-occlusive disease, the histological hallmark of SOS $(27,29)$. Importantly, SOS may also occur in CRC patients that receive oxaliplatin- or irinotecan-based regimes (30), which is the clinical setting for many SIRT-treated patients.

REILD is an uncommon event. Incidence rates of 5.4\% (31) and 4\% (32) have been reported on large series with a mix of tumour types. REILD appears mainly, if not exclusively, in two groups: non-cirrhotic patients exposed to systemic chemotherapy prior to SIRT and treated in a 
whole liver-fashion because of extensive tumour load (e.g. colorectal or breast cancer patients treated in a salvage setting), and patients with cirrhosis and reduced liver functional reserve, even if treated in a more selective fashion (e.g. patients with HCC) (31). The risk of REILD is increased if patients are exposed to chemotherapy in the 2-month period following SIRT (31), in the presence of a small liver (total volume <1.5 L)(31) or increased baseline bilirubin and AST (31), after an intense treatment $(16,31)$, and with repeated whole-liver SIRT (16). In many patients, the disease may be controlled by therapy, but severe complications including overt liver failure may rapidly ensue (33). Although there are no reports on prospective long-term follow-up of patients with REILD, median survival as short as 95 days from SIRT has been reported (32). For any SIRT centre, the outcomes of a regular review and/or an audit process are essential to identify whether complication rates are within the expected limits reported in the recent literature $(6,31)$. There is no clear indication that the occurrence of REILD is different for resin or glass microspheres although the highest incidence of liver decompensation (36.5\% at 6 months) has been reported after SIRT using glass microspheres in intermediate or advanced HCC patients

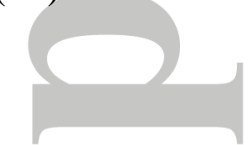

SIRT may produce subclinical liver injury. A significant although clinically irrelevant increase in total bilirubin has been reported in CRC (35), breast cancer (36), and HCC (37) patients. The implications of this subclinical liver damage on the tolerability of subsequent treatments are not known and require further investigation in well designed, prospective studies. 
Non-cirrhotic portal hypertension may very rarely develop months to years after SIRT. Early asymptomatic increases in splenic volume with or without low platelet count are frequently observed, even after lobar SIRT $(32,36,38)$. Similar findings may be seen in patients treated with adjuvant FOLFOX for stage II-III CRC due to sinusoidal injury (39). Gastro-oesophageal varices have been anecdotally identified years after SIRT (40). Histological findings observed in these patients indicate nodular regenerative hyperplasia (unpublished data) with (40), or without (29) bridging fibrosis. Encephalopathy or variceal bleeding have not been reported in noncirrhotic patients.

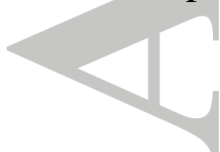

Biliary tree damage

Biliary tree injury post-SIRT has been reported unfrequently, including bile duct necrosis or strictures. Among 569 SIRT treatments in 327 patients, 3 patients (1\%) developed large bilomas requiring drainage (41) while asymptomatic biliary necrosis and strictures were observed in $3.9 \%$ and $2.4 \%$, respectively. In this large series, biliary complications were more common in metastatic disease with multiple disseminated tumours than in primary HCC. Bile duct compression by tumours cannot be ruled out in many cases. The consensus, based on expert opinion, is that SIRT is unlikely to be the primary cause of isolated biliary strictures. This is partially supported by recent evidence of minimal or no significant biliary complications with SBRT or high-dose hypofractionated radiation therapy for tumours located within the perihilar region (42-44). Ischemic cholangitis leading to diffuse biliary strictures has only once been reported after SIRT (45).

\section{Prevention of REILD}


Patients with poor liver functional reserve as those that present with a total bilirubin $>2 \mathrm{mg} / \mathrm{dL}$ or have non-tumoural ascites should not be considered candidates to SIRT. Individual yet conservative decisions should be made in patients with bilirubin values slightly below this threshold in which a rapid increase is observed within the weeks previous to SIRT evaluation.

Adaptation of the calculated activity is recommended in all cases where patients may have a low functional liver reserve because of steatosis, steatohepatitis, hepatitis, or cirrhosis, where the liver is small $(<1.5 \mathrm{~L})$ and in patients who have received multiple lines of prior chemotherapy. Both the type and duration of prior systemic treatment are important, with anecdotal evidence, for example, that the more hepatotoxic therapies used for the treatment of breast cancer may increase the risk of REILD.

The BSA formula is the recommended method for calculating the prescribed activity for SIRT using resin microspheres while for glass microspheres activity is calculated from the volume of liver that is targeted. There is general agreement that BSA formula may overestimate the activity and liver toxicity is lower when the prescribed activity is reduced (6). A tailored treatment protocol has recommended a dual strategy of either more selective lobar or segmental treatment (enabling a greater spared liver volume) or a reduction in the prescribed activity for patients receiving whole-liver SIRT (31). Tables that display a modified BSA formula according to tumour load and lung-shunt have been used in large clinical trials in CRC patients (13).

Both for resin and glass microspheres, the development of reliable dosimetric methods for activity prescription represent the holy grail $(5,46,47)$. Dosimetric analysis indicates that better 
tumour responses are associated with higher mean absorbed doses. From the safety perspective, however, the use of dosimetric methods faces several problems including heterogeneous distribution of particles in the non-tumoural liver, potential changes in particle distribution between MAA and ${ }^{90} \mathrm{Y}$ microsphere injections due to catheter position and local haemodynamic conditions (48), or suboptimal measurement of the tumour to non-tumour ratio for multinodular tumours. Such methods may, however, be reliable for prescribing the activity to patients receiving selective treatment if the tumour to non-tumour uptake ratios of ${ }^{90} \mathrm{Y}$-microspheres can be calculated accurately $(31,49)$. But they have not been validated in prospective trials and are not appropriate for whole-liver treatment, nor for tumours without significant uptake of MAA.

Sequential lobar treatment (i.e. deferring treatment of the contralateral liver lobe for 6 weeks) may improve liver tolerance to SIRT for several reasons. By deferring subclinical liver injury in the contralateral lobe it may lower the likelihood of clinical decompensation. By increasing contralateral lobe volume it may reduce the relative intensity of treatment in that lobe. It provides clinicians with an opportunity to evaluate of the tolerability of SIRT and modify activity prescribed to the contralateral lobe. And finally, the induction of hepatocyte growth factor and other pro-regenerative factors after lobar SIRT (37) might make the contralateral lobe more tolerant to SIRT (50). As a major counterpart, sequential lobar treatment increases treatmentderived costs of an already costly therapy. Small case series have suggested that this approach resulted in fewer grade 3/4 toxicities and liver damage (51) but it has not proved to improve strong outcomes including overall survival. General recommendation should therefore await prospective validation and cost-economic analysis. 
Prophylactic treatments such as pentoxifylline, ursodeoxycholic acid, and low molecular weight heparin (LMWH) have been evaluated to reduce the liver damage caused by conditioning total body irradiation regimens prior to bone marrow transplantation with equivocal results (52-54). Pentoxifylline prevents activation of stellate and endothelial cells by interfering with TGF-beta signalling; LMWH may prevent thrombosis; and ursodeoxycholic acid protects endothelial cells from injury (55) and hepatocytes from cytokine-induced damage (56) while it is known that SIRT is followed by a systemic inflammatory response (37).

Building on this concept, the combination of ursodeoxycholic acid (300 mg twice daily) and methylprednisolone ( 8 to $4 \mathrm{mg}$ once a day) was incorporated into a tailored treatment protocol that also included changes in the algorithm for activity calculation. Prophylactic drug therapy was not independently predictive of the reduced incidence of liver decompensation. In a recent small prospective study, the incidence of focal radiation-induced liver damage at 6 weeks was significantly lowered when patients were treated with pentoxifylline, ursodeoxycholic acid and low-dose LMWH after image-guided interstitial brachytherapy for lmCRC (57). Although ursodeoxycholic acid and low-dose steroids are generally innocuous, currently there is insufficient evidence to recommend prophylactic medication to reduce the incidence of REILD after SIRT.

\section{Recommended diagnostic work-up for suspected REILD}

REILD has to be considered in any patient, cirrhotic or not, that develops jaundice and ascites within the first 3 months after SIRT. Patients may be instructed to provide the result of blood tests including total bilirubin, alkaline phosphatase and transaminases 4 to 6 weeks post-SIRT, as 
well as to report on the presence of oedema or abdominal swelling. Upon the discovery of bilirubin $>3 \mathrm{mg} / \mathrm{dL}$, the physician should request an abdominal ultrasound to rule out bile duct obstruction and to confirm the presence of ascites and the patency of the portal and hepatic veins, as well as additional blood test to measure liver function including albumin and coagulation factors (at least prothrombin activity). Other laboratory tests such as viral hepatitis markers should be ordered in case of markedly elevated AST/ALT (>1000 IU/mL) or if clinically advised. Contrast-enhanced CT or better MRI scan is recommended to accurately evaluate intraand extra-hepatic tumour progression. If the diagnosis is not obvious based on the result of tests and imaging procedures and the course of the disease is stable or worsening, an early liver biopsy is strongly recommended because it may guide treatment. Biopsy is not recommended for cirrhotic patients since the histological findings may be equivocal (27) and there is increased risk of bleeding. Once the diagnosis of REILD is established, liver function tests should be repeated (at least weekly) to identify those patients that may be in transit to liver insufficiency, with declining coagulation and increasing bilirubin.

\section{Treatment of REILD}

Table 3 summarises the most relevant recommendations. Initial symptomatic therapy should include diuretics (low-dose spironolactone and/or furosemide). Defibrotide, a single-stranded polydeoxy-ribonucleotide with antithrombotic, thrombolytic, anti-inflammatory and antiischaemic properties has been successfully used in veno-occulsive disease post-stem cell transplantation at doses ranging from 10 to $40 \mathrm{mg} / \mathrm{kg}$ over a median of 18 days $(58,59)$. Based on this experience, treatment with defibrotide may be considered in patients with REILD and rapidly increasing bilirubin $(>6 \mathrm{mg} / \mathrm{dL}$ ) or an altered coagulation (decline in prothrombin activity 
with or without low platelet count). If medical treatment is ineffective, prompt transjugular intra-hepatic portosystemic stent-shunt (TIPS) placement is recommended as a potentially lifesaving procedure for patients with ongoing decline in liver function following SIRT. This recommendation is based on largely anecdotal experience with REILD (27) and the collective published literature in life-threatening clinical syndromes resulting from sinusoidal congestion $(60,61)$.

\section{RADIATION CHOLECYSTITIS.}

\section{The medical problem}

Acute cholecystitis is a rare complication of SIRT. Symptoms are characterised by upper right quadrant abdominal pain, nausea or vomiting, malaise and occasionally, fever. On the other hand, a thickened gallbladder wall is occasionally observed in patients that remain asymptomatic. In a detailed analysis of CT changes in the gallbladder following SIRT, thickening and hyper-enhancement of the gallbladder wall was observed in 10 out of 42 patients (90\% had metastases adjacent to the gallbladder). These features were most prominent on the first follow-up scan at 20-30 days after treatment (62). The incidence and natural history of gallbladder toxicity are largely unknown, but less than 10 cases of acute cholecystitis have been reported in the literature, and only five in detail $(63,64)$. Surprisingly, in 4 out of these 10 cases, review of MAA and 90Y SPECT images did not reveal increased radioisotope uptake in the gallbladder (64). Cholecystectomy was performed in 7 of these patients without any serious complication $(41,63-65)$.

\section{Critical assessment of current recommendations for prevention of cholecystitis}


Gallbladder imaging changes are largely asymptomatic, but the deposition of 90Y-microspheres in the gallbladder should also be avoided to maximise the delivery of microspheres to the target tumour tissue. As a general rule, placement of the catheter distal to the cystic artery is recommended and only if this is not feasible, temporary occlusion of the cystic artery may be performed preferably immediately before SIRT injecting Gelfoam particles (66) or inducing a vasospasm of the cystic artery using a microwire (67). Coil embolisation of the cystic artery (which may induce acute ischemic cholecystitis (68)) or preventive cholecystectomy are not recommended.

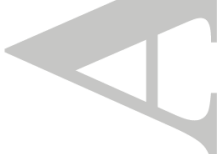

\section{Relevance of subclinical damage to the gallbladder}

On imaging, some shrinkage of the gallbladder may be evident 6 months post-SIRT, but this is not thought to be clinically significant.

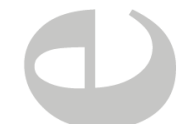

\section{Prevention by medical therapy of acute cholecystitis}

Empiric preventative measures using steroids and antibiotics in patients judged to be at risk of cholecystitis (based on scans during the pretreatment work-up) (67) are not recommended.

\section{Recommended diagnostic work-up for radiation cholecystitis}

Radiation cholecystitis should be suspected in any patient that develops persistent right upper quadrant tenderness and fever 4- to 6-weeks following SIRT. The presence of a thickened ( $\geq 3.5 \mathrm{~mm})$ wall with pericholecystic fluid, intramural gas or hydrops on ultrasound, MRI or CT helps confirm the diagnosis. A thickened, hyper-enhanced gallbladder wall alone should not prompt a diagnosis of cholecystitis in the absence of consistent signs on physical examination, 
including Murphy's sign. If re-evaluation of the MAA scan, Brehmsstralung SPECT scan or 90Y-PET reveals no evidence of intense gallbladder uptake, cholecystitis is highly unlikely. In such cases, an upper endoscopy may be needed to differentiate cholecystitis from gastric and duodenal ulcerations.

\section{Recommended treatment for radiation cholecystitis}

As summarized in Table 4, conservative therapy includes IV hydration and analgesics, while steroids are not recommended. Patients with fever, intense pain, or signs of wall necrosis or rupture on imaging should be considered for cholecystostomy (drainage of the gallbladder) and/or cholecystectomy. Cholecystectomy is the mainstay of the treatment of acalculous cholecystitis but patients who are critically ill or at high risk for surgical complications are better managed by percutaneous cholecystostomy and eventually delayed cholecystectomy. In cancer patients, incorporation of the surgical risk and the patient-specific survival and the impact of antineoplastic therapy in the decision making process may be beneficial (69).

\section{OTHER POTENTIAL COMPLICATIONS}

In a minority of patients, SIRT can be followed by acute symptoms during or shortly after infusion that resemble the post-embolization syndrome observed after TACE and is probably due to the embolizing nature of the radioactive beads. In large series of HCC and CRC patients, reported rates are $13-39 \%$ for abdominal pain, $2-12 \%$ for fever and $17-32 \%$ for nausea and/or vomiting $(7,70-72)$. They are usually mild, last for a few hours and are easily managed by medical treatment including non-narcotic analgesics (paracetamol $1 \mathrm{~g}$ with or without codeine phosphate $30-60 \mathrm{mg}$ orally or IV) or ondansetron (8 mg orally or IV). 


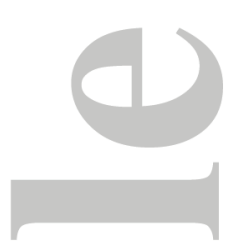

There is no strong published evidence that patients with a "violated ampulla" due to stenting, papillotomy or surgical biliary bypass are at increased risk of infectious complications.

Nevertheless, these patients are usually considered as having a relative contraindication to SIRT and are therefore underrepresented in large cohorts. The expert consensus is that biliary tree instrumentation should not be considered an absolute contraindication for SIRT but treatment should not be conducted in patients with a history of previous sepsis or biliary drainage without prophylactic antibiotics.

Initially, there was a concern that SIRT might increase the morbidity of subsequent liver resection or transplantation. A specific study addressing this question in which 100 patients have been analysed (71 liver resections and 29 transplantations) has shown that the reported rates of complications do not differ much from what can be expected if the patients were operated without prior SIRT (73).

\section{CONCLUSIONS}

Selective internal radiation therapy is used to treat patients with primary and secondary liver cancer. The vast majority of patients have no or mild procedure-related symptoms. If a significant amount of radioactive particles reach non-targeted organs such as the lung, the GI tract or the gallbladder, the radiation may produce tissue damage. This will occur rarely if the procedure is performed to adequate quality assurance standards. However, a certain amount of radiation is always delivered to the non-tumoural liver tissue irrigated by the artery in which the 
microspheres are administered. Again, this will only rarely lead to complications if the recommendations of the manufacturers are followed to calculate the amount of radioactivity that should be injected. It should be noted that some patients have livers that are more sensitive to radiation or have a reduced liver functional reserve and they are at greater risk of clinically significant tissue damage. The impact of radiation-induced tissue damage on patient's health ultimately depends of the damage induced by the treatment and, quite importantly, in the relevance of the organ involved. Pneumonitis is a potentially fatal but exceptionally rare complication. REILD is uncommon but also potentially life-threatening. GI ulcers and cholecystitis may impact quality of life but generally have less severe implications.

Local practices used to prevent and treat such complications vary between centres. In this article, we have extensively analysed the literature to identify the incidence, natural course and risk factors for all these main four complications as well as the relevance of subclinical damage to the corresponding tissues. Based on the available evidence, we have provided recommendations and proposed new medical approaches. Specific recommendations have been made for the diagnostic work-up and treatment of complications induced by SIRT. We believe that this expert guidance may help multidisciplinary teams and individual physicians to make sound decisions with the aim of improving care for patients with primary and secondary malignancies of the liver.

\section{REFERENCES}

1. Lin M. Radiation pneumonitis caused by yttrium-90 microspheres: radiologic findings. AJR Am J Roentgenol 1994;162:1300-1302.

2. Leung TW, Lau WY, Ho SK, Ward SC, Chow JH, Chan MS, Metreweli C, et al. Radiation pneumonitis after selective internal radiation treatment with intraarterial 90yttriummicrospheres for inoperable hepatic tumors. Int J Radiat Oncol Biol Phys 1995;33:919-924. 
3. Wright CL, Werner JD, Tran JM, Gates VL, Rikabi AA, Shah MH, Salem R. Radiation pneumonitis following yttrium-90 radioembolization: case report and literature review. J Vasc Interv Radiol 2012;23:669-674.

4. Gaba RC, Vanmiddlesworth KA. Chemoembolic hepatopulmonary shunt reduction to allow safe yttrium-90 radioembolization lobectomy of hepatocellular carcinoma. Cardiovasc Intervent Radiol 2012;35:1505-1511.

5. Ho S, Lau WY, Leung TW, Chan M, Johnson PJ, Li AK. Clinical evaluation of the partition model for estimating radiation doses from yttrium-90 microspheres in the treatment of hepatic cancer. Eur J Nucl Med 1997;24:293-298.

6. Kennedy AS, Ball D, Cohen SJ, Cohn M, Coldwell DM, Drooz A, Ehrenwald E, et al. Multicenter evaluation of the safety and efficacy of radioembolization in patients with unresectable colorectal liver metastases selected as candidates for (90)Y resin microspheres. J Gastrointest Oncol 2015;6:134-142.

7. Sangro B, Carpanese L, Cianni R, Golfieri R, Gasparini D, Ezziddin S, Paprottka PM, et al. Survival after yttrium-90 resin microsphere radioembolization of hepatocellular carcinoma across Barcelona clinic liver cancer stages: a European evaluation. Hepatology 2011;54:868878.

8. Peterson JL, Vallow LA, Johnson DW, Heckman MG, Diehl NN, Smith AA, Tzou KS, et al. Complications after $90 \mathrm{Y}$ microsphere radioembolization for unresectable hepatic tumors: An evaluation of 112 patients. Brachytherapy 2013;12:573-579.

9. Bradley J, Movsas B. Radiation pneumonitis and esophagitis in thoracic irradiation. Cancer Treat Res 2006;128:43-64.

10. Carretero C, Munoz-Navas M, Betes M, Angos R, Subtil JC, Fernandez-Urien I, De la Riva S, et al. Gastroduodenal injury after radioembolization of hepatic tumors. Am J Gastroenterol 2007;102:1216-1220.

11. Lam MG, Banerjee S, Louie JD, Abdelmaksoud MH, Iagaru AH, Ennen RE, Sze DY. Root cause analysis of gastroduodenal ulceration after yttrium- 90 radioembolization. Cardiovasc Intervent Radiol 2013;36:1536-1547.

12. Rodriguez-Lago I, Carretero C, Herraiz M, Subtil JC, Betes M, Rodriguez-Fraile M, Sola JJ, et al. Long-term follow-up study of gastroduodenal lesions after radioembolization of hepatic tumors. World J Gastroenterol 2013;19:2935-2940.

13. van Hazel GA, Heinemann V, Sharma NK, Findlay MP, Ricke J, Peeters M, Perez D, et al. SIRFLOX: Randomized Phase III Trial Comparing First-Line mFOLFOX6 (Plus or Minus Bevacizumab) Versus mFOLF0X6 (Plus or Minus Bevacizumab) Plus Selective Internal Radiation Therapy in Patients With Metastatic Colorectal Cancer. J Clin Oncol 2016;34:17231731.

14. Chua TC, Bester L, Saxena A, Morris DL. Radioembolization and systemic chemotherapy improves response and survival for unresectable colorectal liver metastases. J Cancer Res Clin Oncol 2011;137:865-873.15. Bester L, Meteling B, Pocock N, Pavlakis N, Chua TC, Saxena A, Morris DL. Radioembolization versus standard care of hepatic metastases: comparative retrospective cohort study of survival outcomes and adverse events in salvage patients. J Vasc Interv Radiol 2012;23:96-105.

16. Kennedy AS, McNeillie P, Dezarn WA, Nutting C, Sangro B, Wertman D, Garafalo M, et al. Treatment parameters and outcome in 680 treatments of internal radiation with resin $90 \mathrm{Y}$ microspheres for unresectable hepatic tumors. Int J Radiat Oncol Biol Phys 2009;74:14941500.

17. Moreno-Luna LE, Yang JD, Sanchez W, Paz-Fumagalli R, Harnois DM, Mettler TA, Gansen DN, et al. Efficacy and safety of transarterial radioembolization versus chemoembolization in patients with hepatocellular carcinoma. Cardiovasc Intervent Radiol 2013;36:714-723. 
18. Sabet A, Ahmadzadehfar H, Schafer N, Wilhelm K, Schuller H, Ezziddin S. Survival after accidental extrahepatic distribution of Y90 microspheres to the mesentery during a radioembolization procedure. Cardiovasc Intervent Radiol 2012;35:954-957.

19. Ulenaers $M$, Dedeurwaerdere F, Christiaens P. Gastric ulceration complicating selective internal radiation therapy of liver metastases. Clin Gastroenterol Hepatol 2010;8:A18.

20. Zimmermann L, Dudeck O, Schmitt J, Ricke J, Roessner A, Malfertheiner P, Monkemuller K. Duodenal ulcer due to yttrium microspheres used for selective internal radiation therapy of hepatocellular cancer. Gastrointest Endosc 2009;69:977-978.

21. Luo DL, Chan JK. Basophilic round bodies in gastric biopsies little known by pathologists: iatrogenic yttrium 90 microspheres deriving from selective internal radiation therapy. Int J Surg Pathol 2013;21:535-537.

22. Thamboo TP, Wai CT, Lim LG, Wang SC. Late gastric ulceration and cytomegalovirus infection following selective internal radiation therapy (SIRT) of the liver. Pathology 2008;40:303-305.

23. Yarze JC, Hoffman MM. Another case of severe, chronically symptomatic, nonhealing gastroduodenal injury after radioembolization of hepatic tumor. Am J Gastroenterol 2007;102:2863.

24. Wallstabe I, Bakos G, Plotner A, Kretzschmar A, Wegner D, Hohdorf K, Scheibe J. Gastroduodenal ulceration after selective internal radiation therapy of liver tumor. Endoscopy 2012;44 Suppl 2 UCTN:E354-355.

25. Kooby DA, Egnatashvili V, Srinivasan S, Chamsuddin A, Delman KA, Kauh J, Staley CA, 3rd, et al. Comparison of yttrium-90 radioembolization and transcatheter arterial chemoembolization for the treatment of unresectable hepatocellular carcinoma. J Vasc Interv Radiol 2010;21:224-230.

26. Zorzi D, Laurent A, Pawlik TM, Lauwers GY, Vauthey JN, Abdalla EK. Chemotherapyassociated hepatotoxicity and surgery for colorectal liver metastases. Br J Surg 2007;94:274286.

27. Sangro B, Gil-Alzugaray B, Rodriguez J, Sola I, Martinez-Cuesta A, Viudez A, Chopitea A, et al. Liver disease induced by radioembolization of liver tumors: description and possible risk factors. Cancer 2008;112:1538-1546.

28. Lawrence TS, Robertson JM, Anscher MS, Jirtle RL, Ensminger WD, Fajardo LF. Hepatic toxicity resulting from cancer treatment. Int J Radiat Oncol Biol Phys 1995;31:1237-1248.

29. Wang LM, Jani AR, Hill EJ, Sharma RA. Anatomical basis and histopathological changes resulting from selective internal radiotherapy for liver metastases. J Clin Pathol 2013;66:205211.

30. Tamandl D, Klinger M, Eipeldauer S, Herberger B, Kaczirek K, Gruenberger B, Gruenberger T. Sinusoidal obstruction syndrome impairs long-term outcome of colorectal liver metastases treated with resection after neoadjuvant chemotherapy. Ann Surg Oncol 2011;18:421-430.

31. Gil-Alzugaray B, Chopitea A, Inarrairaegui M, Bilbao JI, Rodriguez-Fraile M, Rodriguez J, Benito A, et al. Prognostic factors and prevention of radioembolization-induced liver disease. Hepatology 2013;57:1078-1087.

32. Lam MG, Louie JD, Iagaru AH, Goris ML, Sze DY. Safety of repeated yttrium-90 radioembolization. Cardiovasc Intervent Radiol 2013;36:1320-1328.

33. Hamoui N, Ryu RK. Hepatic radioembolization complicated by fulminant hepatic failure. Semin Intervent Radiol 2011;28:246-251.

34. Mazzaferro V, Sposito C, Bhoori S, Romito R, Chiesa C, Morosi C, Maccauro M, et al. Yttrium-90 radioembolization for intermediate-advanced hepatocellular carcinoma: a phase 2 study. Hepatology 2013;57:1826-1837.

35. Piana PM, Gonsalves CF, Sato T, Anne PR, McCann JW, Bar Ad V, Eschelman DJ, et al. Toxicities after radioembolization with yttrium-90 SIR-spheres: incidence and contributing risk factors at a single center. J Vasc Interv Radiol 2011;22:1373-1379. 
36. Paprottka PM, Schmidt GP, Trumm CG, Hoffmann RT, Reiser MF, Jakobs TF. Changes in normal liver and spleen volume after radioembolization with (90)Y-resin microspheres in metastatic breast cancer patients: findings and clinical significance. Cardiovasc Intervent Radiol 2011;34:964-972.

37. Fernandez-Ros N, Inarrairaegui M, Paramo JA, Berasain C, Avila MA, Chopitea A, Varo N, et al. Radioembolization of hepatocellular carcinoma activates liver regeneration, induces inflammation and endothelial stress and activates coagulation. Liver Int 2015;35:1590-1596.

38. Fernandez-Ros N, Silva N, Bilbao JI, Inarrairaegui M, Benito A, D'Avola D, Rodriguez M, et al. Partial liver volume radioembolization induces hypertrophy in the spared hemiliver and no major signs of portal hypertension. HPB (Oxford) 2014;16:243-249.

39. Overman MJ, Maru DM, Charnsangavej C, Loyer EM, Wang H, Pathak P, Eng C, et al. Oxaliplatin-mediated increase in spleen size as a biomarker for the development of hepatic sinusoidal injury. J Clin Oncol 2010;28:2549-2555.

40. Ayav A, Habib N, Jiao LR. Portal hypertension secondary to 90Yttrium microspheres: an unknown complication. J Clin Oncol 2005;23:8275-8276.

41. Atassi B, Bangash AK, Lewandowski RJ, Ibrahim S, Kulik L, Mulcahy MF, Murthy R, et al. Biliary sequelae following radioembolization with Yttrium-90 microspheres. J Vasc Interv Radiol 2008;19:691-697.

42. Yu JI, Park HC, Lim DH, Paik SW. Do Biliary Complications after Hypofractionated Radiation Therapy in Hepatocellular Carcinoma Matter? Cancer Res Treat 2015.

43. Eriguchi T, Takeda A, Sanuki N, Oku Y, Aoki Y, Shigematsu N, Kunieda E. Acceptable toxicity after stereotactic body radiation therapy for liver tumors adjacent to the central biliary system. Int J Radiat Oncol Biol Phys 2013;85:1006-1011.

44. Barney BM, Olivier KR, Miller RC, Haddock MG. Clinical outcomes and toxicity using stereotactic body radiotherapy (SBRT) for advanced cholangiocarcinoma. Radiat Oncol 2012;7:67.

45. Ng SS, Yu SC, Lai PB, Lau WY. Biliary complications associated with selective internal radiation (SIR) therapy for unresectable liver malignancies. Dig Dis Sci 2008;53:2813-2817.

46. Chiesa C, Mira M, Maccauro M, Romito R, Spreafico C, Sposito C, Bhoori S, et al. A dosimetric treatment planning strategy in radioembolization of hepatocarcinoma with $90 \mathrm{Y}$ glass microspheres. Q J Nucl Med Mol Imaging 2012;56:503-508.

47. Garin E, Lenoir L, Rolland Y, Edeline J, Mesbah H, Laffont S, Poree P, et al. Dosimetry based on 99mTc-macroaggregated albumin SPECT/CT accurately predicts tumor response and survival in hepatocellular carcinoma patients treated with 90Y-loaded glass microspheres: preliminary results. J Nucl Med 2012;53:255-263.

48. Aramburu J, Anton R, Rivas A, Ramos JC, Sangro B, Bilbao JI. Liver cancer arterial perfusion modelling and CFD boundary conditions methodology: a case study of the haemodynamics of a patient-specific hepatic artery in literature-based healthy and tumour-bearing liver scenarios. Int J Numer Method Biomed Eng 2016.

49. Kao YH, Tan EH, Ng CE, Goh SW. Clinical implications of the body surface area method versus partition model dosimetry for yttrium-90 radioembolization using resin microspheres: a technical review. Ann Nucl Med 2011;25:455-461.

50. Chi CH, Liu IL, Lo WY, Liaw BS, Wang YS, Chi KH. Hepatocyte growth factor gene therapy prevents radiation-induced liver damage. World J Gastroenterol 2005;11:1496-1502.

51. Seidensticker R, Seidensticker M, Damm R, Mohnike K, Schutte K, Malfertheiner P, Van Buskirk M, et al. Hepatic toxicity after radioembolization of the liver using (90)Ymicrospheres: sequential lobar versus whole liver approach. Cardiovasc Intervent Radiol 2012;35:1109-1118. 
52. Clift RA, Bianco JA, Appelbaum FR, Buckner CD, Singer JW, Bakke L, Bensinger WI, et al. A randomized controlled trial of pentoxifylline for the prevention of regimen-related toxicities in patients undergoing allogeneic marrow transplantation. Blood 1993;82:2025-2030.

53. Ohashi K, Tanabe J, Watanabe R, Tanaka T, Sakamaki H, Maruta A, Okamoto S, et al. The Japanese multicenter open randomized trial of ursodeoxycholic acid prophylaxis for hepatic veno-occlusive disease after stem cell transplantation. Am J Hematol 2000;64:32-38.

54. Rosenthal J, Sender L, Secola R, Killen R, Millerick M, Murphy L, Cairo MS. Phase II trial of heparin prophylaxis for veno-occlusive disease of the liver in children undergoing bone marrow transplantation. Bone Marrow Transplant 1996;18:185-191.

55. Ishida $H$, Nakayasu $H$, Tsuji K. Study of the pharmacological effect of the bile salt, sodium scymnol sulfate, from Rhizoprionodon acutus. IV. Effects of naturally occurring bile alcohols, bile acids and their conjugates on lesion development and vascular endothelial cell injury in a rat peripheral arterial occlusion model. Biol Pharm Bull 1999;22:828-835.

56. Neuman MG, Shear NH, Bellentani S, Tiribelli C. Role of cytokines in ethanol-induced cytotoxicity in vitro in Hep G2 cells. Gastroenterology 1998;115:157-166.

57. Seidensticker M, Seidensticker R, Damm R, Mohnike K, Pech M, Sangro B, Hass P, et al. Prospective randomized trial of enoxaparin, pentoxifylline and ursodeoxycholic acid for prevention of radiation-induced liver toxicity. PLoS One 2014;9:e112731.

58. Richardson PG, Murakami C, Jin Z, Warren D, Momtaz P, Hoppensteadt D, Elias AD, et al. Multiinstitutional use of defibrotide in 88 patients after stem cell transplantation with severe veno-occlusive disease and multisystem organ failure: response without significant toxicity in a high-risk population and factors predictive of outcome. Blood 2002;100:4337-4343.

59. Chopra R, Eaton JD, Grassi A, Potter M, Shaw B, Salat C, Neumeister P, et al. Defibrotide for the treatment of hepatic veno-occlusive disease: results of the European compassionate-use study. Br J Haematol 2000;111:1122-1129.

60. Senzolo M, Cholongitas E, Patch D, Burroughs AK. TIPS for veno-occlusive disease: is the contraindication real? Hepatology 2005;42:240-241; author reply 241.

61. Campos-Varela I, Castells L, Dopazo C, Perez-Lafuente M, Allende H, Len O, Llopart L, et al. Transjugular intrahepatic portosystemic shunt for the treatment of sinusoidal obstruction syndrome in a liver transplant recipient and review of the literature. Liver Transpl 2012;18:201-205.

62. Miller FH, Keppke AL, Reddy D, Huang J, Jin J, Mulcahy MF, Salem R. Response of liver metastases after treatment with yttrium-90 microspheres: role of sise, necrosis, and PET. AJR Am J Roentgenol 2007;188:776-783.

63. Thamboo T, Tan KB, Wang SC, Salto-Tellez M. Extra-hepatic embolisation of Y-90 microspheres from selective internal radiation therapy (SIRT) of the liver. Pathology 2003;35:351-353.

64. Parakh S, Gananadha S, Allen R, Yip D. Cholecystitis after yttrium-90 resin microsphere radioembolisation treatment: Clinical and pathologic findings. Asian J Surg 2015.

65. Jakobs TF, Hoffmann RT, Dehm K, Trumm C, Stemmler HJ, Tatsch K, La Fougere C, et al. Hepatic yttrium-90 radioembolisation of chemotherapy-refractory colorectal cancer liver metastases. J Vasc Interv Radiol 2008;19:1187-1195.

66. Ahmadzadehfar H, Sabet A, Biermann K, Muckle M, Brockmann H, Kuhl C, Wilhelm K, et al. The significance of 99mTc-MAA SPECT/CT liver perfusion imaging in treatment planning for 90Ymicrosphere selective internal radiation treatment. J Nucl Med 2010;51:1206-1212.

67. Lenoir L, Edeline J, Rolland Y, Pracht M, Raoul JL, Ardisson V, Bourguet P, et al. Usefulness and pitfalls of MAA SPECT/CT in identifying digestive extrahepatic uptake when planning liver radioembolisation. Eur J Nucl Med Mol Imaging 2012;39:872-880. 
68. McWilliams JP, Kee ST, Loh CT, Lee EW, Liu DM. Prophylactic embolisation of the cystic artery before radioembolisation: feasibility, safety, and outcomes. Cardiovasc Intervent Radiol 2011;34:786-792.

69. Jayakrishnan TT, Groeschl RT, George B, Thomas JP, Pappas S, Gamblin TC, Turaga KK. Management of acute cholecystitis in cancer patients: a comparative effectiveness approach. Surg Endosc 2014;28:1505-1514.

70. Salem R, Lewandowski RJ, Mulcahy MF, Riaz A, Ryu RK, Ibrahim S, Atassi B, et al. Radioembolization for hepatocellular carcinoma using Yttrium-90 microspheres: a comprehensive report of long-term outcomes. Gastroenterology 2010;138:52-64.

71. Hickey R, Lewandowski RJ, Prudhomme T, Ehrenwald E, Baigorri B, Critchfield J, Kallini J, et al. 90Y Radioembolization of Colorectal Hepatic Metastases Using Glass Microspheres: Safety and Survival Outcomes from a 531-Patient Multicenter Study. J Nucl Med 2016;57:665-71.

72. Kennedy AS, Ball D, Cohen SJ, Cohn M, Coldwell DM, Drooz A, Ehrenwald E, et al. Multicenter evaluation of the safety and efficacy of radioembolization in patients with unresectable colorectal liver metastases selected as candidates for (90)Y resin microspheres. J Gastrointest Oncol 2015;6:134-42.

73. Pardo F, Schön M, Lee RC, Manas D, Jeyarajah R, Katsanos G, Maleux G, et al.The Post-SIRSpheres Surgery Study (P4S): Analysis of Outcomes following Hepatic Resection or Transplantation in 100 Patients Previously Treated with Selective Internal Radiation Therapy (SIRT). Proceedings of the Annual Conference of the Americas Hepato-Pancreato-Biliary Association. 2015 p. 127.

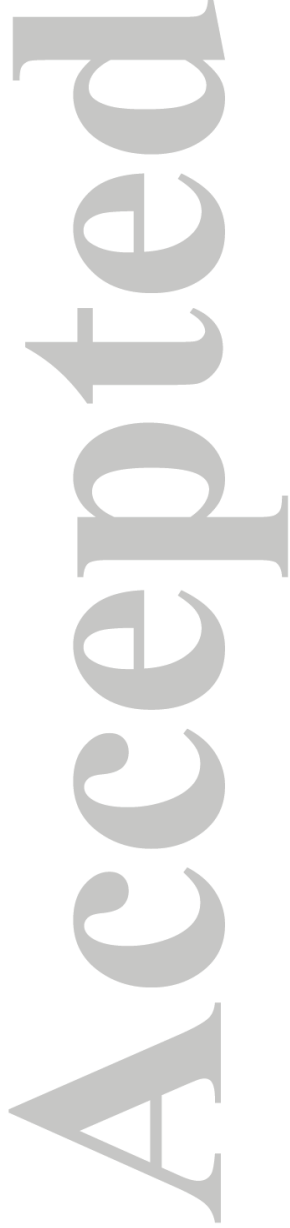




\section{Figure legends}

Figure 1. Superselective SIRT was indicated in a patient with hepatocellular carcinoma that had a $27 \%$ lung shunt fraction based on pre-treatment MAA scan (A). A dose of 0.5 GBq of resin microspheres was prescribed that should have resulted in an estimated dose of radiation to the lungs of $7 \mathrm{~Gy}$. A higher exposure was suspected based on the post-SIRT Brehmsstralung-SPECT images (B). Cough, dyspnea and hypoxemia developed 22 days after SIRT. Chest X-ray (C) and

CT scan (D) showed the typical pattern of radiation pneumonitis, which was fatal in this case.

Figure 2. A 39-year-old patient with liver metastases from a pancreatic neuroendocrine tumor developed extensive GI ulcerations 4 weeks after SIRT (A) through the left hepatic artery. Clinical symptoms took more than 3 months to resolve, but complete healing was observed at month 12 . The patient remains symptomless and with no relevant gastric abnormalities 8 years later (B).

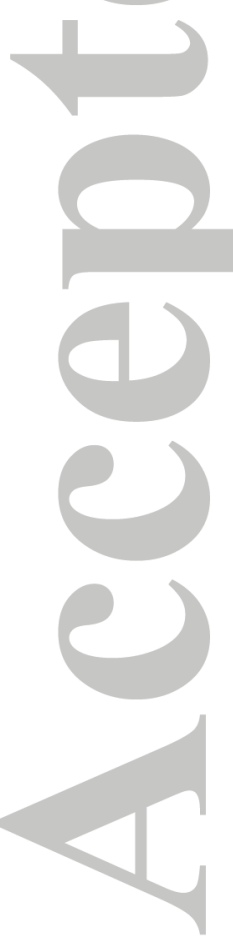


Table 1. Expert advice on prevention, diagnostic work-up and treatment of radiation pneumonitis

\begin{tabular}{|c|c|c|}
\hline Prevention & Work-up & Treatment \\
\hline $\begin{array}{l}\text { Reductions of } 20 \%, 40 \% \text { and } \\
100 \% \text { in injected activity if lung } \\
\text { shunt exceeds } 10 \%, 15 \% \text { or } \\
20 \% \text {, respectively (for resin } \\
\text { microspheres). } \\
\text { Dose of radiation to lung tissue } \\
\text { under } 30 \text { Gy based on MAA } \\
\text { scan (for resin or glass } \\
\text { microspheres). } \\
\text { If lung shunt is } \geq 15 \% \text {, strongly } \\
\text { consider an alternative } \\
\text { treatment approach (balance } \\
\text { between safety and efficacy). }\end{array}$ & $\begin{array}{l}\text { Chest CT scan if hypoxemia, } \\
\text { cough or dyspnoea within the } \\
\text { first } 2 \text { months post-SIRT, } \\
\text { particularly if lung shunt on } \\
\text { MAA scan was }>10 \% \text {. } \\
\text { Functional tests to confirm } \\
\text { restrictive pattern and altered } \\
\text { carbon monoxide diffusion level } \\
\text { (DLCO). } \\
\text { The decision to perform a } \\
\text { broncho-alveolar lavage and/or } \\
\text { a transbronchial lung biopsy } \\
\text { should be based on the } \\
\text { likelihood of alternative } \\
\text { diagnosis. }\end{array}$ & $\begin{array}{l}\text { Steroids on a very empiric basis } \\
\text { (methylprednisolone } 500 \mathrm{mg} \text { IV bid } \\
\text { or prednisolone } 60 \mathrm{mg} \mathrm{PO} \text { and } \\
\text { slow tapering). } \\
\text { Oxygen supply as needed. }\end{array}$ \\
\hline
\end{tabular}


Table 2. Expert advice on prevention, diagnostic work-up and treatment of radiation-induced GI ulcers

\begin{tabular}{|c|c|c|}
\hline Prevention & Work-up & Treatment \\
\hline $\begin{array}{l}\text { Conventional or CT angiography } \\
\text { to identify hepaticoenteric } \\
\text { vessels, and avoid them by coil } \\
\text { embolization, a more distal } \\
\text { injection or flow redistribution. } \\
\text { SIRT simulation using MAA test } \\
\text { with } \\
\text { - Perchlorate to avoid false } \\
\text { positive gastric uptake. } \\
\text { MAA prepared within } 30 \\
\text { minutes before injection. } \\
\text { Injection from the same } \\
\text { site as treatment. } \\
\text { SPECT imaging performed } \\
\text { within } 1 \text { hour after } \\
\text { injection. } \\
\text { If a false-positive result is } \\
\text { suspected, repeat MAA test } \\
\text { before contraindicating SIRT. } \\
\text { Use isotonic dextrose } 5 \% \text { as the } \\
\text { administrative agent for resin } \\
\text { microspheres. } \\
\text { IA lidocaine or nitroglycerine may } \\
\text { ameliorate vasospasm during } \\
\text { SIRT. }\end{array}$ & $\begin{array}{l}\text { Upper endoscopy in every } \\
\text { patient who develops upper } \\
\text { abdominal pain } 4 \text { to } 8 \text { weeks } \\
\text { after SIRT, particularly if } \\
\text { associated with nausea, loss of } \\
\text { appetite or anaemia (even if no } \\
\text { extrahepatic uptake of } \\
\text { radioactivity in the MAA } \\
\text { SPECT/CT or 90Y-PET scans). } \\
\text { Presumptive diagnosis based on } \\
\text { gross morphology (multiple } \\
\text { erosions and ulcerations or a } \\
\text { single large ulcer, with diffuse } \\
\text { mucositis, usually involving the } \\
\text { distal gastric body, antrum, } \\
\text { pylorus and the duodenal bulb). } \\
\text { Biopsies not mandatory unless } \\
\text { an alternative cause is } \\
\text { considered. }\end{array}$ & $\begin{array}{l}\text { High-dose proton pump } \\
\text { inhibitors (Omeprazole } 40 \text { mg } \\
\text { daily or equivalent doses of } \\
\text { Pantoprazole, Lansoprazole, etc), } \\
\text { Sucralfate, antiemetics, } \\
\text { analgesics, and gastric } \\
\text { promotility agents } \\
\text { (Domperidone or Cinitapride). } \\
\text { Avoid nonsteroidal anti- } \\
\text { inflammatory drugs and any } \\
\text { other medications that may } \\
\text { produce gastritis or ulcers. } \\
\text { In more severe cases consider } \\
\text { total parenteral nutrition or } \\
\text { jejunostomy. }\end{array}$ \\
\hline
\end{tabular}


Table 3. Expert advice on prevention, diagnostic work-up and treatment of REILD

\begin{tabular}{|c|c|c|}
\hline Prevention & Work-up & Treatment \\
\hline $\begin{array}{l}\text { Contraindicate if total bilirubin } \\
>2 \mathrm{mg} / \mathrm{dL} \text { or non-tumoural } \\
\text { ascites. Consider individually late } \\
\text { changes in bilirubin. } \\
\text { Consider reducing the } \\
\text { recommended activity for } \\
\text { patients with chronic liver } \\
\text { disease (including } \\
\text { steatohepatitis or cirrhosis), } \\
\text { where the liver is }<1.5 \text { L, and in } \\
\text { patients who have received } \\
\text { multiple prior chemotherapy } \\
\text { regimes. } \\
\text { Spare as many liver segments as } \\
\text { appropriate and technically } \\
\text { feasible. }\end{array}$ & $\begin{array}{l}\text { Suspect REILD in any patient } \\
\text { that develops jaundice and } \\
\text { ascites within the first } 3 \text { months } \\
\text { after SIRT. } \\
\text { Request US-doppler to check for } \\
\text { bile duct obstruction, ascites, } \\
\text { and portal/hepatic vein patency, } \\
\text { plus blood test to measure liver } \\
\text { damage and function (ASAT, } \\
\text { ALAT, alkaline phosphatase, } \\
\text { total bilirubin, albumin, INR). If } \\
\text { bile duct obstruction is } \\
\text { discarded, request contrast- } \\
\text { enhanced CT or (better) MRI to } \\
\text { rule out tumor progression. } \\
\text { Repeat LFTs at least weekly. If } \\
\text { the problem persists or worsens } \\
\text { within } 2 \text { weeks consider liver } \\
\text { biopsy (only for non-cirrhotic } \\
\text { patients) and consultation with } \\
\text { Hepatologist. }\end{array}$ & $\begin{array}{l}\text { Treat initially with diuretics } \\
\text { (Spironolactone } 100 \text { mg and/or } \\
\text { Furosemide } 40 \text { mg daily) and } \\
\text { adjust the dose based on weight } \\
\text { loss and renal function. } \\
\text { If liver function starts to decline } \\
\text { (for instance, total bilirubin } \geq 6 \\
\text { mg/dL and prothrombin activity } \\
\leq 60 \% \text { or INR } \geq 1.4 \text { ), consider } \\
\text { Defibrotide IV at a starting dose } \\
\text { of } 10 \text { mg/kg. } \\
\text { If liver failure develops despite } \\
\text { medical treatment, consider } \\
\text { transjugular intra-hepatic } \\
\text { portosystemic stent-shunt (TIPS) } \\
\text { placement. }\end{array}$ \\
\hline
\end{tabular}

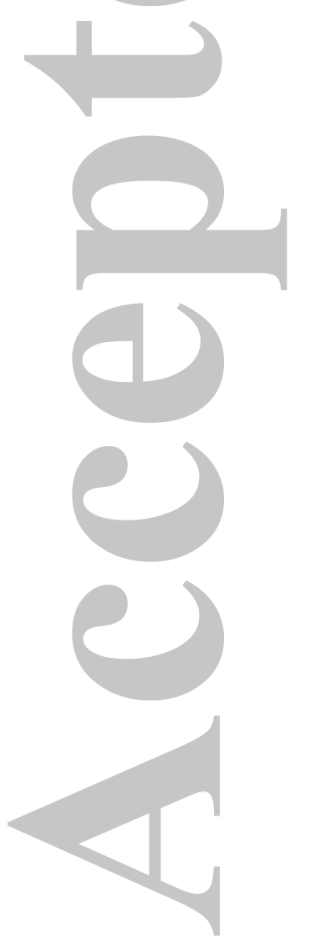


Table 4. Expert advice on prevention, diagnostic work-up and treatment of radiation cholecystitis

\begin{tabular}{|l|l|l|}
\hline Prevention & Work-up & Treatment \\
\hline $\begin{array}{l}\text { When a significant amount of } \\
\text { activity is likely to be diverted to } \\
\text { the gallbladder and to maximise } \\
\text { the delivery of microspheres to } \\
\text { the tumour, place the catheter } \\
\text { distal to the cystic artery. }\end{array}$ & $\begin{array}{l}\text { Suspect radiation cholecystitis in } \\
\text { any patient with persistent right } \\
\text { upper quadrant tenderness 4- to } \\
\text { 6-weeks following SIRT. The } \\
\text { presence of a thickened ( } \geq\end{array}$ & $\begin{array}{l}\text { Provide IV hydration and } \\
\text { analgesics on demand. } \\
\text { Consider cholecystostomy } \\
\text { (preferred) or cholecystectomy in } \\
\text { patients with fever, intense pain, } \\
\text { fluid, intramural gas or hydrops } \\
\text { on imaging may confirm the } \\
\text { rupture on imaging. }\end{array}$ \\
$\begin{array}{l}\text { If this is not feasible, perform } \\
\text { temporary occlusion of the } \\
\text { cystic artery using microwire- } \\
\text { induced vasospasm or Gelfoam } \\
\text { particles immediately before } \\
\text { SIRT. }\end{array}$ & $\begin{array}{l}\text { signs on physical examination } \\
\text { (Murphy). }\end{array}$ & $\begin{array}{l}\text { Weight surgical risk, patient- } \\
\text { specific survival and the impact of } \\
\text { antineoplastic therapy before } \\
\text { taking a surgical decision. }\end{array}$ \\
\hline
\end{tabular}




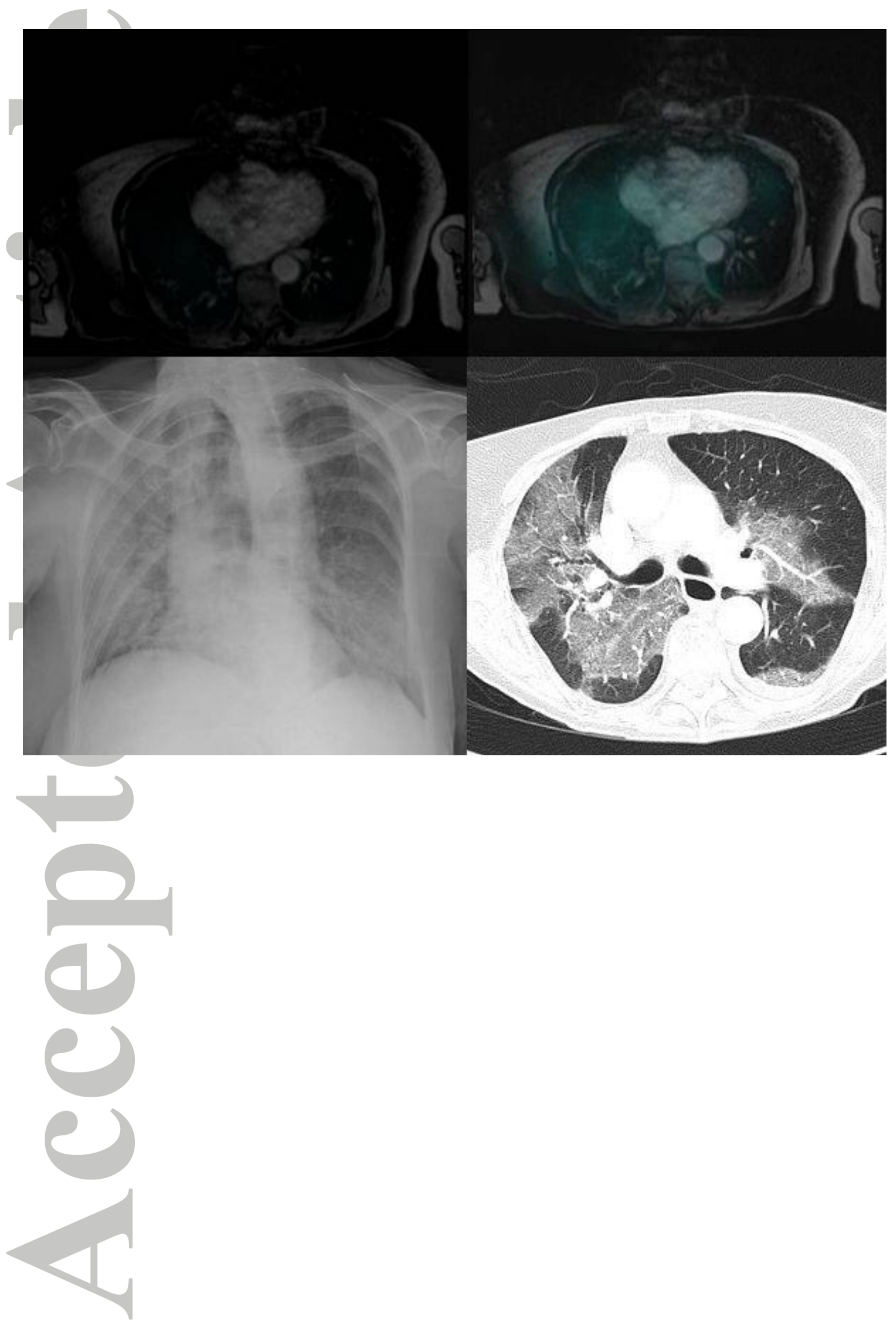

This article is protected by copyright. All rights reserved. 

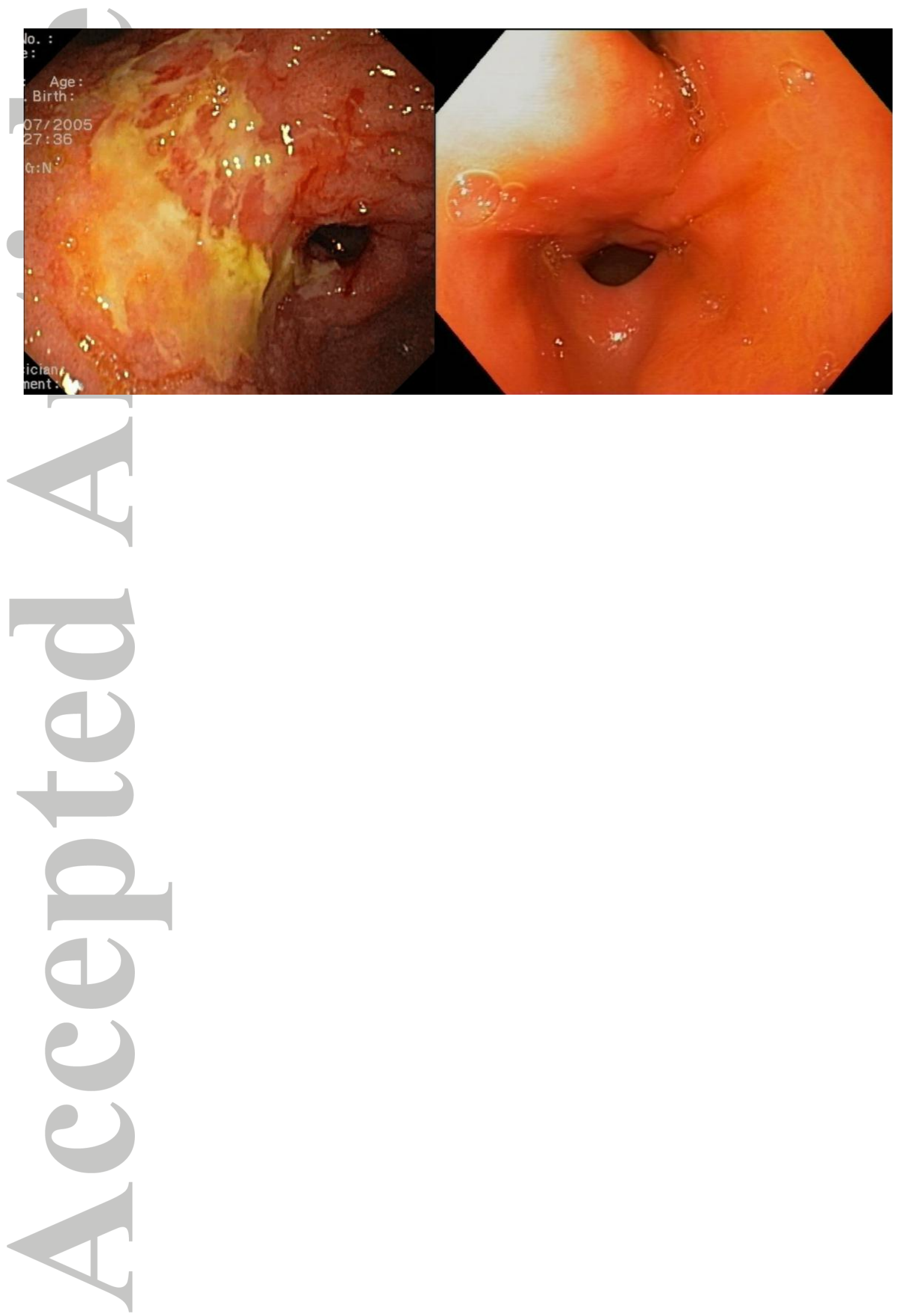

This article is protected by copyright. All rights reserved. 



This article is protected by copyright. All rights reserved. 